\title{
NILAI STABILITAS POROUS ASPHALT MENGGUNAKAN MATERIAL LOKAL
}

\author{
Mirza Ghulam R. ${ }^{1}$, Wahyu Nariswari ${ }^{1}$, Enes Ariyanto S. ${ }^{1}$, Tri Gunawan ${ }^{2}$ \\ ${ }^{1}$ Staf Pengajar Program Studi Teknik Sipil Politeknik Negeri Banyuwangi \\ ${ }^{2}$ Mahasiswa Diploma III Politeknik Negeri Banyuwangi \\ Jl. Raya Jember KM.13, Kabat Banyuwangi 68461. Email: mirza@poliwangi.ac.id
}

\begin{abstract}
ABSTRAK
Asphalt Porous adalah campuran aspal dengan kadar pasir yang rendah untuk mendapatkan ruang pori yang tinggi. Permasalahan perkerasan asphalt porous dengan gradasi terbuka (open graded) secara umum terletak pada nilai struktural perkerasan seperti nilai stabilitas yang masih rendah dibandingkan dengan perkerasan gradasi rapat (dense graded). Penelitian ini secara umum bertujuan untuk mengetahui kinerja perkerasan campuran aspal berpori dengan menggunakan aspal penetrasi 60/70

Analisis kinerja fungsi kekuatan campuran aspal berpori dilakukan dengan Marshall Test dengan membandingkan hasil pengujian parameter seperti stabilitas, void in mixture (vim), kelelehan (flow), dan marshall question. Untuk analisis model resapan campuran aspal berpori dilakukan dengan metode Falling Head Permeability (FHP), dimana air didalam tabung (stand pipe) jatuh bebas dengan ketinggian tertentu sampai melewati rongga pada campuran aspal berpori menggunakan rentang kadar aspal variasi rencana antara lain 4,0\%, 4,5\%, 5,0\%, 5,5\%, dan 6,0\%.

Hasil penelitian didapat kadar aspal optimum 5,0 \% pada campuran asphalt porous. Stabilitas asphalt porous dari lima variasi kadar aspal rata-rata yaitu $1.123,61 \mathrm{Kg}$. Untuk nilai rata-rata VIM pada lima variasi kadar aspal yaitu 23,22 \%. Nilai rata-rata flow pada lima variasi kadar aspal 4,68 mm. Dan untuk nilai marshall question $241,82 \mathrm{Kg} / \mathrm{mm}$. Semakin besarnya rongga udara pada open graded asphalt (OGA) maka semakin kecil nilai stabilitas-nya. Hasil penelitian permeabilitas asphalt porous pada lima variasi kadar aspal rata-rata yaitu $0,367 \mathrm{~cm} / \mathrm{s}$.
\end{abstract}

Kata kunci: Porous Asphalt, karakteristik, marshall, open graded, permeabilitas.

\section{Pendahuluan}

Menurut spesifikasi campuran beraspal Direktorat Jenderal Bina Marga edisi November 2010 Revisi III, Perkerasan Lentur (Flexible Pavement) adalah sistem perkerasan jalan dimana konstruksinya terdiri dari beberapa lapisan. Lapisan perkerasan fungsinya untuk menyebarkan beban roda kendaraan sehingga dapat di tahan oleh tanah dasar dalam batas daya dukungnya.

Genangan air hujan diatas perkerasan jalan yang selalu terjadi pada musim penghujan, mengakibatkan gangguan kenyamanan pengendara. Karakter flexible pavement yang kedap terhadap air dan drainase yang buruk sepanjang jalan, mendukung fenomena tersebut. Hal tersebut mengurangi resapan air hujan dan mempercepat kerusakan jalan.
Asphalt porous merupakan salah satu inovasi untuk meningkatkan resapan air hujan pada tanah dan untuk mengurangi adanya genangan diatas jalan. Fungsi Asphalt Porous biasanya di gunakan pada fasilitas parkir kendaraan ringan, dan jalan kecil (Perumahan). Menurut Saleh M.Sofyan; (2014) yang di sebutkan dalam Australian Asphalt Pavement Association/AAPA, (2004) Asphalt Porous harus di letakkan di lapisan permukaan jalan sebagai lapisan yang bersifat non struktural dan di atas lapis pondasi yang kedap air (Asphalt Treated Base).

Konstruksi perkerasan Asphalt Porous merupakan salah satu alternatif dari perkerasan lentur (Flexible Pavement) dengan tujuan memberikan ke leluasaan air melakukan Penetrasi ke dalam lapisan permukaan atas (Surface Layer) secara Vertikal dan Horizontal 
serta menyalurkannya dalam sistem drainase perkerasan. Perkerasan Asphalt Porous memiliki banyak keuntungan bagi penggunaan jalan dan lingkungan, seperti fungsi drainase dan menjaga keselamatan serta mengurangi tingkat kebisingan (Sugeng, 2003). Menurut Flexible Pavement of OHIO, Asphalt Porous di gunakan pada: Fasilitas Parkir Kendaraan Ringan, dan Jalan Kecil (Jalan Perumahan).

Perkerasan dengan aspal konvensional (dense graded) berkinerja cukup baik, terutama dengan nilai struktural dalam hal stabilitas. Disisi lain, perkerasan tersebut juga mengalami banyak persoalan, seperti terjadinya aquaplqnning sehingga jalan cukup licin serta tingkat kekasaran permukaaan jalan yang relatif kurang. Konstruksi perkerasan aspal porus mempakan salah satu alternatif dari perkerasan lentur (flexible pavement) dengan tujuan memberikan keleluasaan air melakukan penetrasi ke dalam lapisan permukaan atas (surface layer) secara vertikal dan horizontal serta menyalurkannya dalam sistem drainase perkerasan (Muh. Nahsir, 2013).

\section{Studi Pustaka}

Menurut Jauhari, 2013 keuntungan penggunaan Asphalt Porous antara lain dapat mengurangi Aquaplaning apabila permukaan aspal basah akibat tingginya kadar pori dalam Asphalt Porous. Permukaan Asphalt Porous sangat kasar dan kesat sehingga nilai Skid Resistance (tahanan geser) tinggi yang dapat mengurangi kecelakaan lalu lintas berupa slipnya ban kendaraan di atas permukaan jalan. Asphalt porous mampu meresapkan air pada arah
Vertical dan Horizontal dan mengalirkannya ke saluran samping jalan sehingga air tidak mempengaruhi lapisan Subbase. Dapat meredam kebisingan kendaraan $3-4 \mathrm{~dB}$, di mana kebisingan tersebut diredam oleh pori pori yang ada dalam Asphalt Porous. Sistem drainase Asphalt porous ditunjukkan pada Gambar 1.

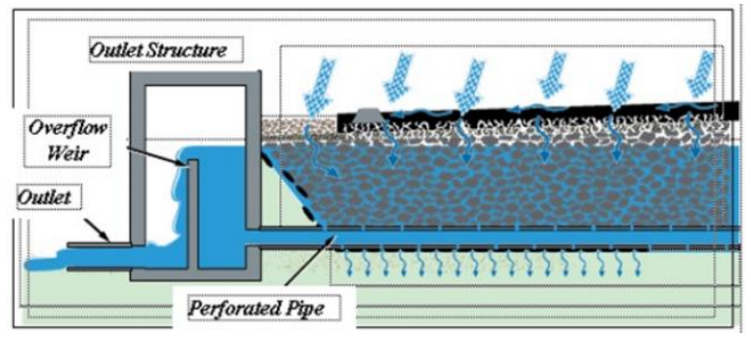

Gambar 1. Sistem drainase Asphalt Porous (National Asphalt Pavement Association, 2006)

\section{Lapisan Asphalt Porous}

Aspal untuk lapis Asphalt Porous pada penelitian ini terdiri dari salah satu aspal keras dengan Penetrasi 60/70 yang seragam dan tidak mengandung air, apabila di panaskan sampai dengan $175^{\circ} \mathrm{C}$ tidak berbusa, dan memenuhi persyaratan sebagai yang tercantum pada Tabel 1 Persyaratan Aspal Keras.

\section{Gradasi Agregat Asphalt Porous}

Beberapa gradasi agregat pada asphalt porous menggunakan standart yang yang ditetapkan oleh Australian Asphalt Pavement Association (AAPA, 2004).

Tabel 1. Persyaratan Aspal Keras

\begin{tabular}{|c|c|c|c|c|c|c|c|}
\hline \multirow[t]{3}{*}{ No } & \multirow{3}{*}{ Jenis Pemeriksaaan } & \multirow{3}{*}{$\begin{array}{c}\text { Cara } \\
\text { Pemeriksaan } \\
\text { (MPBJ) }\end{array}$} & \multicolumn{4}{|c|}{ Persyaratan } & \multirow[t]{3}{*}{ Satuan } \\
\hline & & & \multicolumn{2}{|c|}{ Pen. 60} & \multicolumn{2}{|c|}{ Pen. 80} & \\
\hline & & & Min & Mak & Min & Mak & \\
\hline 1 & Penetrasi $\left(25^{0}\right.$ C 5 detik $)$ & PA 0301-76 & 60 & 79 & 80 & 99 & $0.1 \mathrm{~mm}$ \\
\hline 2 & Titik Lembek (Ring Ball) & PA 0302-76 & 48 & 58 & 46 & 54 & ${ }^{0} \mathrm{C}$ \\
\hline 3 & Titik Nyala (Clev Open Cup) & PA 0303-76 & 200 & - & 225 & - & ${ }^{0} \mathrm{C}$ \\
\hline 4 & Kehilangan Berat $\left(163^{0} \mathrm{C}, 5\right.$ jam $)$ & - & - & 0.8 & - & 0.1 & $\%$ berat \\
\hline 5 & Kelarutan $\left(\mathrm{C}_{2} 11 \mathrm{CL}_{3}\right)$ & PA 0305-76 & 99 & - & 99 & - & $\%$ berat \\
\hline 6 & Daktilitas $\left(25^{\circ} \mathrm{C}, 5 \mathrm{~cm} /\right.$ menit $)$ & PA 0306-76 & 100 & - & 100 & - & $\mathrm{cm}$ \\
\hline 7 & Penetrasi Setelah Kehilangan Berat & PA 0301-76 & 54 & - & 50 & - & $\%$ semula \\
\hline 8 & Daktalitas Setelah Kehilangan Berat & PA 0306-76 & 50 & - & 75 & - & $\mathrm{cm}$ \\
\hline 9 & Berat Jenis $\left(25^{0} \mathrm{C}\right)$ & PA $0307-76$ & 1 & - & 1 & - & $\mathrm{gr} / \mathrm{cc}$ \\
\hline
\end{tabular}

Sumber: SNI 03-1737-1989 (Tentang Tata Cara Pelaksanaan Lapis Aspal Beton/Laston Untuk Jalan Raya). 
Tabel 2. Ketentuan Campuran Asphalt Porous

\begin{tabular}{|c|c|c|}
\hline No. & Kriteria Perencanaan & Nilai \\
\hline 1 & Koefisien Permeabilitas $(\mathrm{cm} / \mathrm{s})$ & $\mathbf{0 , 1}-\mathbf{0 , 5}$ \\
\hline 2 & Kadar Rongga di Dalam Campuran $($ VIM $\%)$ & $\mathbf{1 8}-\mathbf{2 5}$ \\
\hline 3 & Stabilitas Marshall $(\mathrm{kg})$ & Min. 500 \\
\hline 4 & Kelelehan Marshall $(\mathrm{mm})$ & $\mathbf{2}-\mathbf{6}$ \\
\hline 5 & Marshall Question $(\mathrm{Kg} / \mathrm{mm})$ & Maks. 400 \\
\hline 6 & Jumlah Tumbukan Perbidang & $\mathbf{5 0}$ \\
\hline
\end{tabular}

Sumber: Australian Asphalt Pavement Association (AAPA), 2004.

Bahan pengikat yang digunakan adalah Aspal Penetrasi 60/70. Sedangkan urutan saringan yang digunakan adalah 1 set saringan berukuran $19 \mathrm{~mm} ; 12,5 \mathrm{~mm} ; 9,5 \mathrm{~mm} ; 4,75 \mathrm{~mm} ; 2,36 \mathrm{~mm}$; $0,6 \mathrm{~mm} ; 0,3 \mathrm{~mm} ; 0,15 \mathrm{~mm} ; 0,075 \mathrm{~mm}$, di mana saringan yang paling kasar di letakkan di atas dan yang paling halus terletak paling bawah. Satu set saringan di mulai dari pan dan di akhiri dengan tutup.

Penggunaan gradasi agregat untuk campuran Asphalt Porous harus sesuai dengan batas batas dari gradasi yang di gunakan, yaitu tidak boleh melebihi dari batas atas dan batas bawah dari sebuah gradasi dengan total $100 \%$.

Kinerja Asphalt Porous di peroleh melalui hasil pengujian karakteristik campuran ber aspal. Spesifikasi untuk Asphalt Porous di batasi pada nilai - nilai kriteria perencanaan pada Tabel 2.

Adapun gradasi agregat untuk campuran Asphalt Porous, di tunjukkan dalam persen terhadap berat agregat, harus memenuhi batas dan juga harus mempunyai jarak terhadap batas-batas toleransi, seperti pada Tabel 3.

\section{Estimasi Awal Kadar Aspal}

Setelah proporsi masing - masing agregat di ketahui, maka di lakukan perhitungan kadar aspal optimum perkiraan. Adapun perhitungannya menurut (Depkimpraswil, 2004) sebagai berikut:

$$
\begin{aligned}
P_{b}= & 0,035(\% C A)+0,045(\% F A)+0,18 \\
& (\% F F)+\text { konstanta } \ldots \ldots \ldots \ldots \ldots \ldots \ldots \ldots \ldots \ldots \ldots \ldots \ldots
\end{aligned}
$$

Dengan :

$P_{b} \quad=$ persentasi kadar aspal awal terhadap berat total campuran.

$\% C A=\%$ agregat kasar (Coarse Aggregate) terhadap berat total agregat.

$$
\begin{aligned}
\% F A= & \% \text { agregat halus (Fine Aggregate) } \\
& \text { terhadap berat total agregat. } \\
\% F F= & \% \text { Filler terhadap berat total agregat. } \\
K \quad & \text { Nilai konstanta kira - kira } 0,5-1,0 \\
& \text { untuk Laston dan 2,0-3,0 untuk } \\
& \text { Lataston. Untuk jenis campuran lain } \\
& \text { di gunakan nilai 1,0-2,5. }
\end{aligned}
$$

Tabel 3. Gradasi Agregat Untuk Campuran Asphalt Porous

\begin{tabular}{|c|c|}
\hline $\begin{array}{c}\text { Ukuran } \\
\text { Ayakan }(\mathbf{m m})\end{array}$ & $\begin{array}{c}\text { \% Berat yang Lolos Terhadap } \\
\text { Total Agregat Dalam } \\
\text { Campuran }\end{array}$ \\
\hline 19 & \begin{tabular}{c} 
Lolos Saringan (\%) \\
\hline
\end{tabular} \\
\hline 13,2 & $85-100$ \\
\hline 9,5 & $45-70$ \\
\hline 6,7 & $25-45$ \\
\hline 4,75 & $10-25$ \\
\hline 2,36 & $7-15$ \\
\hline 1,18 & $6-12$ \\
\hline 0,6 & $5-10$ \\
\hline 0,3 & $4-8$ \\
\hline 0,15 & $3-7$ \\
\hline 0,075 & $2-5$ \\
\hline Total & 100 \\
\hline Kadar Aspal & $4 \%-6 \%$ \\
\hline Sumb: Australian
\end{tabular}

Sumber: Australian Asphalt Pavement Association (AAPA), 2004.

\section{Kinerja Permeabilitas Asphalt porous}

Metode pengujian permeabilitas menggunakan benda uji Asphalt Porous di dalam mould yang telah di rendam sampai jenuh. Mould kosong di letakkan di atas mould yang berisi benda uji. Bagian dalam sambungan kedua mould di oles Vaselin, agar air tidak menembus keluar. Ke dalam mould kosong diisi air setinggi $5 \mathrm{~cm}$. Lama waktu perembesan air melalui media Asphalt Porous di catat. Menurut Diana, 1995 
dan Takahashi et all, 1999, permeabilitas horizontal dan vertikal dapat dihitung dengan menggunakan persamaan (2).

$K=2,3 \frac{a \cdot L}{A \cdot t} \cdot \log \frac{h_{1}}{h_{2}}$

\section{Dimana:}

$k=$ Koefisien permeabilitas air $(\mathrm{cm} / \mathrm{s})$.

$a=$ Luas potongan melintang tabung $\left(\mathrm{cm}^{2}\right)$.

$L=$ Tebal spesimen $(\mathrm{cm})$.

$A=$ Luas potongan melintang spesimen $\left(\mathrm{cm}^{2}\right)$.

$\mathrm{t}$ = Waktu yang di butuhkan untuk mengalirkan air dari $\mathrm{h}_{1} \mathrm{ke}_{2}$ (s).

$\mathrm{h}_{1}=$ Tinggi batas air paling atas pada tabung (cm) $h_{1}$.

$\mathrm{h}_{2}=$ Tinggi batas air paling bawah pada tabung $(\mathrm{cm}) \mathrm{h}_{2}$.

\section{Metodologi}

Metode yang digunakan pada penelitian adalah dengan menggunakan metode eksperimental di laboratorium. Selanjutnya di lakukan observasi untuk mengetahui nilai Stabilitas Marshall dan Permeabilitas (Permeability). Material yang di gunakan dalam campuran Asphalt Porous terlebih dahulu dilakukan uji karakteristik agregat dan material pengikat. Material pengikat yang digunakan adalah aspal penetrasi 60/70. Pengujian material pengikat dilakukan dengan mengacu pada SNI 03-1737-1989 dan pengujian ini di lakukan di Laboratorium Bahan Jalan Program Studi Teknik Sipil Politeknik Negeri Banyuwangi. Total benda uji 30 buah dengan 3 benda uji untuk masing-masing variasi kadar aspal.

Fungsi resapan campuran Asphalt porous dilakukan dengan metode Falling Head Permeability dan kinerja fungsi kekuatan campuran Asphalt porous dilakukan dengan metode Marshall.

\section{Analisis dan Pembahasan}

\section{Pengujian karakteristik material}

Hasil pengujian agregat memenuhi standar SNI yang telah ditetapkan, sehingga agregat tersebut dapat digunakan untuk campuran aspal berpori. Untuk rekapitulasi karakteristik agregat ditunjukkan pada Tabel 4.

Tabel 4 Rekapitulasi hasil karakteristik agregat

\begin{tabular}{|c|c|c|c|c|c|}
\hline No. & Karakteristik & $\begin{array}{c}\text { Standart } \\
\text { Pengujian } \\
\text { Agregat Kasar }\end{array}$ & Persyaratan & Hasil & Keterangan \\
\hline 1. & Penyerapan air & SNI 03-1969-1990 & maks. 3\% & 1,469 & Memenuhi \\
\hline 2. & Berat jenis & SNI 03-1970-1990 & min. 2,5 gr/cc & 2,569 & Memenuhi \\
\hline 3. & $\begin{array}{c}\text { Abrasi dengan mesin Los } \\
\text { Angeles }\end{array}$ & SNI 03-2417-1991 & maks. 40\% & 20,770 & Memenuhi \\
\hline 4. & Kelekatan agregat terhadap aspal & SNI 03-2439-1991 & min. 95\% & 98,050 & Memenuhi \\
\hline
\end{tabular}

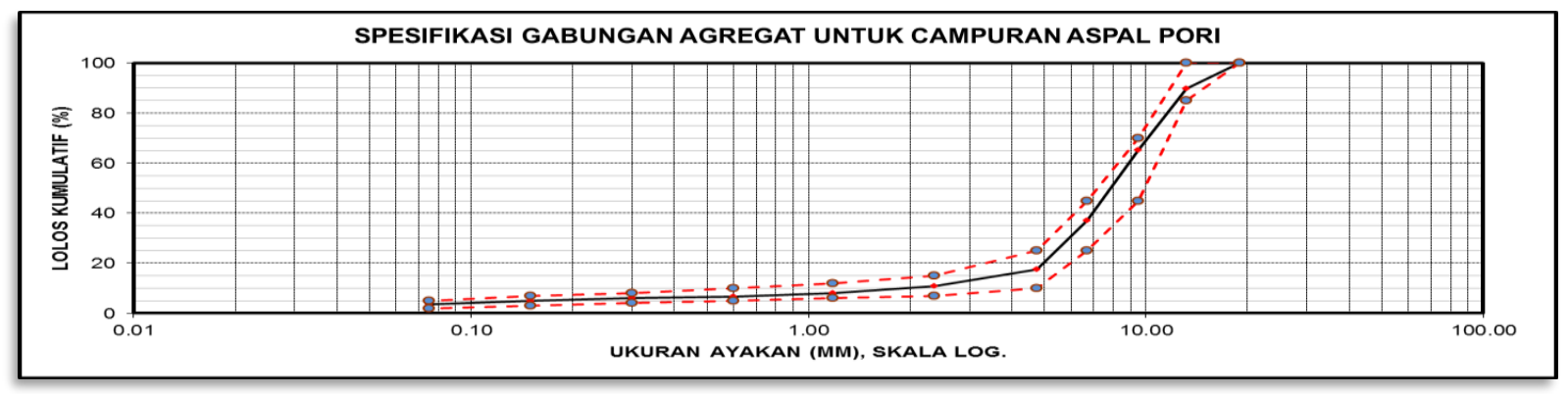

Gambar 2. Gradasi gabungan Aspal Pori 
Grafik gabungan agregat telah memenuhi batas-batas toleransi yang ditetapkan. Berdasar desain gradasi tersebut, selanjutnya dilakukan mix design dan membuat briket benda uji dengan variasi kadar aspal mulai $4,0 \%$ sampai dengan variasi $6,0 \%$.

\section{Pengujian Aspal}

Bahan aspal yang digunakan adalah aspal penetrasi 60/70. Hasil pengujian menunjukkan bahwa bahan pengikat (aspal) telah memenuhi syarat yang ditetapkan (SNI), sehingga bahan pengikat dapat digunakan sebagai campuran aspal berpori. Hasil pengujian ditunjukkan pada Tabel 5.

Tabel 5. Rekapitulasi hasil pengujian aspal

\begin{tabular}{|c|c|c|c|r|c|}
\hline No. & Karakteristik & Standart Pengujian & Persyaratan & Hasil & Keterangan \\
\hline \multicolumn{7}{|c|}{ Aspal } \\
\hline 1. & Penetrasi pada $25^{\circ} \mathrm{C}$ & SNI 06-2456-1991 & $60-70$ & 65,100 & Memenuhi \\
\hline 2. & Titik lembek $\left({ }^{\circ} \mathrm{C}\right)$ & SNI $2434-2011$ & $\geq 48$ & 51,000 & Memenuhi \\
\hline 3. & Titik nyala $\left({ }^{\circ} \mathrm{C}\right)$ & SNI $2433-2011$ & $\geq 232$ & 350,500 & Memenuhi \\
\hline 4. & Berat Jenis & SNI $2441-2011$ & $\geq 1,0$ & 1,030 & Memenuhi \\
\hline
\end{tabular}

\section{Pengujian Kadar Aspal Optimum (KAO)}

Nilai kadar aspal optimum (KAO) ditunjukkan pada Tabel 6.

Tabel 6. Kadar Aspal Optimum (KAO)

\begin{tabular}{|c|c|c|c|c|c|c|}
\hline \multirow{2}{*}{ Karakteristik } & \multirow{2}{*}{ Standart } & \multicolumn{5}{|c|}{ Kadar Aspal } \\
\hline & & $4,0 \%$ & $4,5 \%$ & $5,0 \%$ & $5,5 \%$ & $6,0 \%$ \\
\hline Stabilitas & $\min 500$ & & & A & & \\
\hline Flow & $2-6$ & & & & & \\
\hline$V I M$ & $18-25$ & & & & & \\
\hline Permeabilitas & $0,1-0,5$ & & & & & \\
\hline
\end{tabular}

KAO

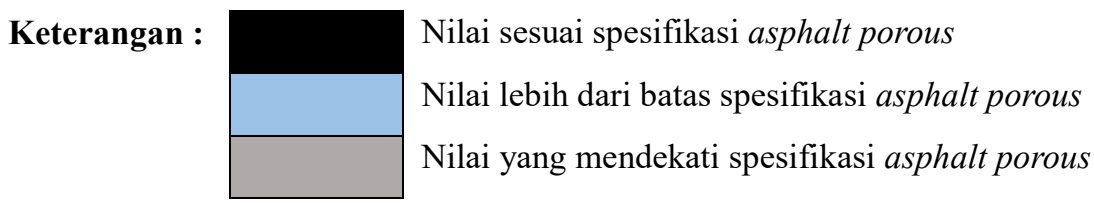

Setelah didapatkan berat agregat kasar per fraksi dan berat kadar aspal per variasi selanjutnya. Pemakaian berat 1200 gram dipakai untuk menentukan open graded asphalt (OGA) atau porous asphalt. 
Tabel 7. Berat aspal dan agregat kasar pada campuran AC-WC

\begin{tabular}{|c|c|c|c|c|c|c|}
\hline \multirow{2}{*}{$\begin{array}{l}\text { Kada } \\
\mathbf{r} \\
\text { Aspal }\end{array}$} & \multirow{2}{*}{$\begin{array}{c}\text { Berat } \\
\text { Aspal } \\
\text { Terhada } \\
\text { p }\end{array}$} & \multicolumn{3}{|c|}{ Mix Design Campuran Agregat } & \multirow{2}{*}{$\begin{array}{c}\text { Total } \\
\text { Agregat } \\
\text { Gabung } \\
\text { an }\end{array}$} & \multirow{2}{*}{$\begin{array}{l}\text { Total Berat } \\
\text { Campuran }\end{array}$} \\
\hline & & $\begin{array}{c}C A \\
(40 \%)\end{array}$ & $\begin{array}{c}M A \\
(40 \%)\end{array}$ & $\begin{array}{c}F A \\
(20 \%)\end{array}$ & & \\
\hline$(\%)$ & (gr) & (gr) & (gr) & (gr) & (gr) & (gr) \\
\hline 4,0 & 48 & 460,8 & 460,8 & 230,4 & 1152 & 1200 \\
\hline 4.5 & 54 & 458,4 & 458,4 & 229,2 & 1146 & 1200 \\
\hline 5,0 & 60 & 456,0 & 456,0 & 228,0 & 1140 & 1200 \\
\hline 5.5 & 66 & 453,6 & 453,6 & 226,8 & 1134 & 1200 \\
\hline 6,0 & 72 & 451,2 & 451,2 & 225,6 & 1128 & 1200 \\
\hline
\end{tabular}

\section{Pengujian Campuran Aspal Berpori}

Setelah melakukan pencampuran agregat pada campuran panas $A C-W C$, selanjutnya dilakukan pembuatan benda uji pada kelima komposisi variasi kadar aspal untuk melihat karakteristik Marshall Question sesuai spesifikasi Asphalt Porous yang meliputi stabilitas, flow, VIM. Hasil pengujian pada setiap variasi kadar aspal dapat dilihat pada Tabel 8 dan Error! Reference source not found. sampai dengan Gambar 3.

Tabel 8. Nilai pengujian Marshall pada Asphalt Porous

\begin{tabular}{|c|c|c|c|c|}
\hline $\begin{array}{c}\text { Variasi } \\
\text { Kadar }\end{array}$ & VIM & Flow & Stabilitas & MQ \\
\hline Aspal & $\mathbf{( \% )}$ & $\mathbf{( m m})$ & $\mathbf{( K g )}$ & $\mathbf{( K g / m m )}$ \\
\hline $4.0 \%$ & 22.3 & 4.7 & 1125.3 & 240.1 \\
\hline $4.5 \%$ & 22.7 & 4.5 & 1136.7 & 253.6 \\
\hline $5.0 \%$ & 21.9 & 4.3 & 1105.5 & 262.1 \\
\hline $5.5 \%$ & 24.3 & 5.0 & 1119.6 & 227.8 \\
\hline $6.0 \%$ & 24.9 & 5.0 & 1131.0 & 225.5 \\
\hline $\begin{array}{c}\text { Spesifikasi } \\
\text { AAPA } \\
\mathbf{2 0 0 4}\end{array}$ & $\mathbf{1 8}-\mathbf{2 5}$ & & $>\mathbf{5 0 0}$ & $\begin{array}{c}\text { Maks. } \\
\mathbf{4 0 0}\end{array}$ \\
\hline
\end{tabular}

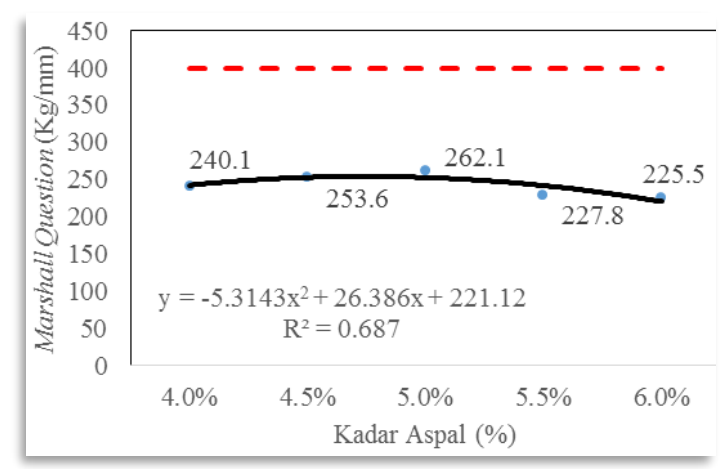

Gambar 3. Grafik hubungan Marshall Question vs Kadar Aspal

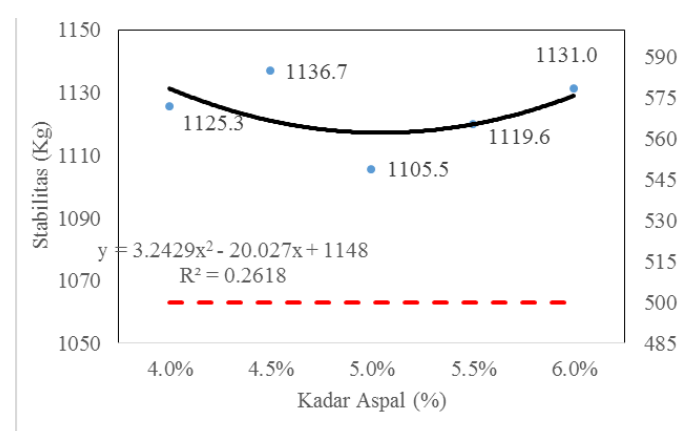

Gambar 4. Grafik hubungan stabilitas vs Kadar Aspal

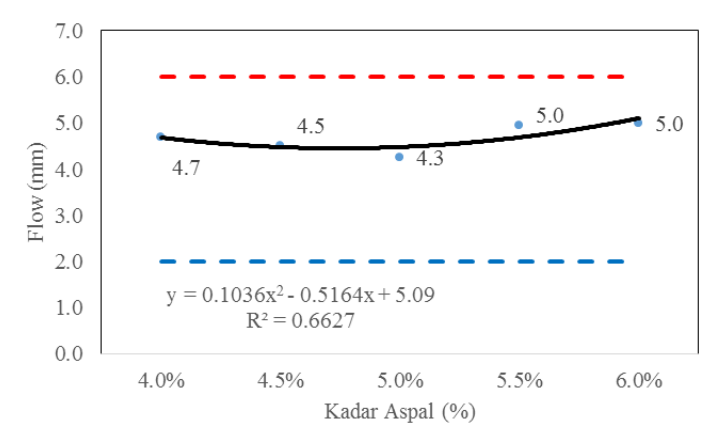

Gambar 5. Grafik hubungan Flow vs Kadar Aspal

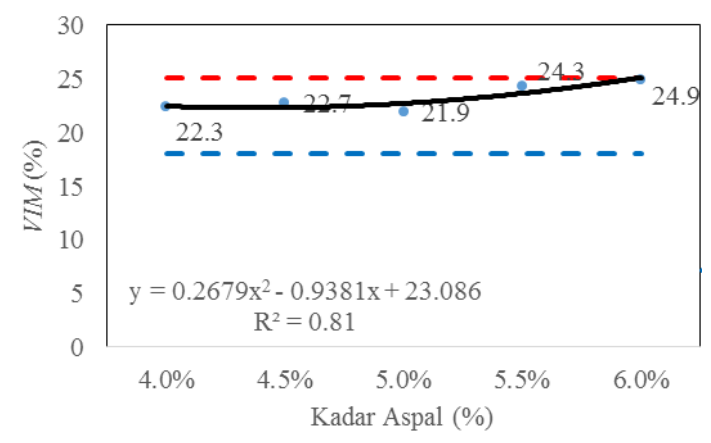

Gambar 6. Grafik hubungan porositas (VIM) vs Kadar Aspal 


\section{Pengujian Permeabilitas Aspal Berpori}

Hasil uji permeabilitas aspal berpori ditunjukkan pada Tabel 9.

Tabel 9. Hasil pengujian permeabilitas

\begin{tabular}{|c|c|c|}
\hline \multicolumn{3}{|c|}{ Hasil Perhitungan Permeabilitas Asphalt } \\
Porous
\end{tabular}

\section{Kesimpulan}

a. Berdasarkan teori, agregat bergradasi senggang memberikan rongga dalam campuran (VIM) yang besar maka menghasilkan nilai stabilitas yang tinggi. Dibuktikan hasil pada kadar aspal 6\% memiliki nilai VIM yang tinggi 24,90\% sehingga nilai stabilitas yang dihasilkan sebesar $1131 \mathrm{Kg}$.

b. Nilai flow yang tinggi mengindikasikan campuran bersifat plastis dan lebih mampu mengikuti deformasi akibat beban. Dibuktikan dari hasil, didapatkan pada kadar 6\% nilai flow diketahui sebesar $5 \mathrm{~mm}$. Semakin betambahnya kadar aspal maka nilai flow yang dihasilkan semakin tinggi.

c. Dari hasil prosentase VIM yang didapatkan pada kadar $6 \%$ menghasilkan nilai prosentase tertinggi dari keseluruhan variasi kadar aspal sebesar $24,9 \%$. Semakin tinggi kadar aspal yang dipakai nilai prosentase VIM yang didapatkan semakin besar.

d. Kenaikan dan penurunan nilai MQ dipengaruhi oleh hasil bagi antara stabilitas dan flow, mengindikasikan pendekatan kekakuan dan fleksibilitas dari suatu campuran aspal. Pada kadar 5,0\% menghasilkan nilai MQ tertinggi sebesar $262,1 \mathrm{Kg} / \mathrm{mm}$.

e. Nilai permeabilitas rata-rata aspal berpori sebesar $0,367 \mathrm{~cm} / \mathrm{s}$ dan memenuhi standar spesifikasi aspal berpori yaitu antara $0,1-0,5$ $\mathrm{cm} / \mathrm{s}$.

\section{DAFTAR PUSTAKA}

AAPA, Australian Asphalt Pavement Association, (1997). Open Graded Asphalt Design Guide, Australia.

Australian Asphalt Pavement Association (AAPA), (2004). National Asphalt Specification.

Australian Asphalt Pavement Association, (2004). Road Engineering Association of Australian joint with Jabatan Kerja Raya Malaysia.

Bina Marga, (1999), Pedoman Teknik No. 028/T/bm/1999, Dinas Pekerjaan Umum Bina Marga.

Diana. I, W., Siswosoebrotho. B. I, Karsaman. R. B. (2009). Sifat-Sifat Teknik dan Permeabilitas pada Aspal Porus. Simposium III FSTPT, ISBN no. 97996241-0-X.

Direktorat Jenderal Bina Marga (2007), Spesikasi Umum Bina Marga 2010 (Revisi III)

Jauhari, Sri Nurul (2013), Karakteristik Marshall Test Pada Lapisan Perkerasan Aspal Berongga Menggunakan Batu Karang Dan Buton Natural Asphalt, Makasar: Skripsi Teknik Sipil Universitas Hasanudin.

Nurcahya, Aldian (2013), Analisis Kinerja Campuran Aspal Porus Menggunakan Aspal Pen 60/70 Dan Aspal Modifikasi Polimer Elvaloy. Program Megister Sistem Teknik dan Jalan Raya Institut Teknologi Bandung. 
PT. Buton Asphalt Indonesia, (2009), Prosedur Perencanaan Campuran (Mix Design) Asphalt Concrete dengan BRA, Jakarta

RSNI M-01-2003. Pedoman Pelaksanaan Lapis Campuran Beraspal Panas. Jakarta.

Sofyan, M. Saleh (2014), Karakteristik Campuran Aspal Porous Dengan Subtitusi Styrofoam Pada Aspal Penetrasi 60/70. Jurnal Teknik Sipil Vol 21.

Standar Nasional Indonesia (SNI). 03-17371989, Tata Cara Pelaksanaan Lapis Aspal Beton (LASTON) Untuk Jalan Raya. Jakarta

Standar Nasional Indonesia (SNI). 06-24891991, Metode Pengujian Campuran Aspal Dengan Alat Marshall. Jakarta.

Sugeng B., et al.(2003). Laboratory Performance Of Porous Asphalt Mixture Using Tafpack Super. Journal of the Eastern Asia Society for Transportation Studies. Vol.5., October.

Sukirman, Silvia (1999), Perkerasan Lentur Jalan Raya, Penerbit Nova, Bandung.

Sukirman, Silvia (2003), Beton Aspal Campuran Panas, Penerbit Granit, Jakarta. 